Thorax (1947), 2, 203.

\title{
COMPLETE OCCLUSION OF THE SUPERIOR VENA CAVA WITH CHRONIC MEDIASTINITIS IN A CASE OF GENERALIZED ACTINOMYCOSIS
}

\author{
BY \\ J. P. D. MOUNSEY \\ Brighton Municipal Hospital \\ [For Plates see page 194]
}

Ochsner and Dixon (1936), in a review of world literature, cited 120 cases of superior vena caval thrombosis. Twenty-eight of these were due to chronic mediastinitis, of which eleven were stated to be due to syphilis, ten to tuberculosis, one to pyogenic infection, one to trauma, and five of unknown aetiology. Tubbs (1946) reported three further cases of superior vena caval obstruction, one of which was probably due to syphilis, the remaining two being of unknown aetiology. Renbourn (1946) reported a case of superior vena caval thrombosis of unknown aetiology, with complete superior vena caval obstruction. The above authorities do not mention actinomycosis as a cause.

Cope (1938) stated that " primary thoracic actinomycosis can and most likely does fairly frequently commence by the fungus penetrating the wall of the oesophagus and reaching the mediastinum." He described two main types, the pulmonary and the mediastinal, and he discussed the general symptoms and signs of thoracic actinomycosis and its complications, but did not mention superior vena caval obstruction among these.

Fischer (1904) gave actinomycosis as the cause of superior vena caval obstruction in 0.5 per cent of cases, but I was unable to trace a copy of this work. Nor was I able to find, in the literature available, any other reported cases of superior vena caval occlusion with chronic mediastinitis due to actinomycosis.

\section{Case Report}

A man, aged 43, whose occupation was parcel clerk, was referred to hospital with a diagnosis of mediastinal abscess.

PAst History.-His history was characterized by its chronicity and diversity, pointing to the involvement of many systems. For five to ten years before admission the patient had been known to have had tachycardia and a dry unproductive cough. During the last two years he had been under observation, and his case was considered at different times to be suggestive of tuberculosis, thyrotoxicosis, and pulmonary or mediastinal new growth. Investigations, which included sputum examination, gland biopsy, and bronchoscopy, failed 
to confirm any of these suspicions. Towards the end of this period he developed signs of superior vena caval obstruction, and a widespread septic skin condition. Most important of all, sinuses appeared on the anterior and posterior chest wall, which discharged intermittently. Curettage for diagnostic purposes was advised and refused.

By February, 1947, severe paroxysmal dyspnoea necessitated admission to hospital.

ON ADMISSION.-He was toxic, cyanosed, and dyspnoeic, but wasting was not marked. His tongue was raw. He had no clubbing of the fingers, He was apyrexial.

Cardiovascular system.-Signs of superior vena caval obstruction were present. The superficial veins of the abdomen were enlarged, draining downwards. There was oedema of the left arm. The veins of the neck and forehead were engorged. The liver edge was just palpable. There was no oedema of the ankles. There was tachycardia, the pulse rate being 126 and rhythm regular. Blood pressure was $120 / 65 \mathrm{~mm}$. $\mathrm{Hg}$.

Respiratory system.- There was evidence of fluid at the left base, and there was diminished air entry over the whole of the left side of the chest.

Sinuses.-Posteriorly over the eighth rib there were two rubbery, smooth, ovoid lumps, which were freely movable, and below these was a healed sinus. Anteriorly and below the xiphisternum there were two more healed sinuses.

Abdomen.-The liver edge was just palpable.

Skin.-There were raised inflamed areas, with central ulceration one to two centimetres in diameter, on the left forearm and on the anterior surface of the right thigh.

Central nervous system.-There were no physical signs.

\section{INVESTIGATIONS}

Radiograph of chest.-There was evidence of a left posterior basal empyema. Both right and left hilar shadows were enlarged. The superior mediastinum was widened. There was evidence of thickened interlobar fissures on the right side (Plate XIV $a$ and $b$ ).

Sputum.-Three specimens were examined and found negative for tubercle bacilli.

Aspiration of left posterior chest.-One pint of thick, green, sickly smelling pus was obtained. The empyema wall was thickened. On culture, the pus was sterile under aerobic conditions; anaerobic culture yielded Gram-negative bacilli.

Blood count.-The blood count was as follows: haemoglobin $66 \%$; red blood cells $3,780,000$ per c.mm. of blood; total leucocytes 16,000 per c.mm. of blood; polymorphonuclears $90 \%$; lymphocytes $9 \%$; monocytes $1 \%$.

A diagnosis of superior vena caval obstruction, due to chronic mediastinitis, with chronic left empyema was made. Tuberculosis, chronic pyogenic infection, and actinomycosis were considered as likely primary aetiological agents on account of the chronicity of the infection and the presence of multiple sinuses, with a secondary anaerobic infection of the empyema.

Rib resection and drainage of the left basal empyema was performed, and section of the wall of the pleura showed much collagenous thickening and some round- and plasmacell infiltration but no evidence of tuberculous infection or neoplasm.

The patient gradually became weaker and more dyspnoeic. He died a fortnight after admission.

Full investigations, including exploration of sinuses, Wassermann reaction, circulation time, venous pressure, phlebogram, etc., were not completed.

\section{POST-MORTEM Findings}

External appearance.-There was no marked wasting. The superficial veins of the chest wall were much dilated. The left arm and right thigh were scarred with pustular raised lesions. 
Mediastinum.-Heart, lungs, pleura, pericardium, and great vessels were adherent and densely bound down by thick white fibrous tissue. The fibrous tissue contained tracks of granulation tissue of honeycomb-like structure. Buried in it were found scattered small abscesses. In other places there was a green, jelly-like exudate. A healed sinus leading to the skin beneath the xiphisternum, containing pus, was traced two inches up into the mediastinum to the right side.

Superior vena cava.-There was total obliteration of the lumen of the superior vena cava for about half an inch immediately superior to its entrance into the right auricle. The lumen of the vein above the obstruction gradually narrowed funnel-fashion, finally becoming totally obliterated by fibrous tissue and granulation tissue of the same honeycomb-like structure.

Heart.-The heart muscle was rather flabby. The pericardium was densely adherent and was also firmly bound to all surrounding structures. There was a small abscess in the wall of the pericardium. The valves were normal, beyond atherosclerosis of the aortic valve.

\section{Respiratory Organs}

Left side.-In the left pleural cavity there were extensive adhesions. There was a thick-walled paravertebral empyema, which had been drained. Sections of the lung did not reveal any abnormal tissue macroscopically. The bronchi appeared normal.

Right side.-In the right pleural cavity there were extensive adhesions on the lateral and mediastinal aspects. A firm gelatinous material existed in the interlobar fissures, in places one centimetre thick, which glued the lobes together. There was a turbid serous effusion and fibrinous exudate on the visceral pleura. Cut sections of the lung did not reveal any macroscopical abnormality. The bronchi appeared normal.

Gastro-intestinal tract.-No abnormality was found.

Liver.-The liver showed early fatty change. There were two small islands of honeycomb-like infiltration both on its anterior surface, one island lying immediately adjacent to the mediastinal sinus beneath the xiphisternum.

Kidneys.-The capsules stripped easily. In the right kidney both cortex and medulla were infiltrated with honeycomb-like tissue which contained a small abscess peripherally.

Spleen.-The spleen was soft, septic, and enlarged. There was a small abscess at the lower pole.

Brain.-There was a small abscess on the inferior surface of the right temporal lobe.

Sections of the mediastinal granulation tissue, granulation tissue obstructing the superior vena cava, pericardium, liver, spleen, kidneys, and brain all revealed typical actinomycosis. Sections of the skin were not taken.

\section{SUMMARY}

1. A short review of the literature of superior vena caval obstruction due to chronic mediastinitis with special reference to actinomycosis is given.

2. A case of complete occlusion of the superior vena cava with chronic mediastinitis due to generalized actinomycosis is described.

\section{REFERENCES}

Cope, Zachary (1938). “Actinomycosis.” London: Oxford Univ. Press, p. 141. Fischer, K. J. (1904). " Ueber Verengerung und Verschliessung der Vena Cava Superior." Diss. Inaug. Halle.

Ochsner, A., and Dixon, J. L. (1936). J. thorac. Surg., 5, 641.

Renbourn, E. T. (1946). Thorax, 1, 257.

Tubbs, Oswald S. (1946). Thorax, 1, 247. 